A cybernetic perspective on the nature of psychopathology: Transcending conceptions of mental illness as statistical deviance and brain disease

\author{
Colin G. DeYoung \\ $\&$ \\ Robert F. Krueger \\ Department of Psychology \\ University of Minnesota \\ 75 East River Rd. \\ Minneapolis, MN 55455
}

IN PRESS: Journal of Psychopathology and Clinical Science

https://doi.org/10.1037/abn0000541

DeYoung Email: cdeyoung@umn.edu

Krueger Email: krueg038@umn.edu 


\begin{abstract}
Explicitly or implicitly, psychopathology is often defined in terms of statistical deviance, requiring that an affected individual is sufficiently distant from the norm in some dimension of psychological or neural function. In recent decades, the dominant paradigm in psychiatric research has focused primarily on deviance in neural function, treating psychopathology as disease of the brain. We argue that these conceptualizations are misguided. We recently proposed a novel theory of psychopathology, based in cybernetics and drawing additionally from neuroscience, psychometrics, and personality theory (DeYoung \& Krueger, 2018a). In this theory, deviations from the norm in psychological and neural functioning serve as important risk factors for psychopathology but are not in themselves necessary or sufficient to identify psychopathology, which requires the presence of cybernetic dysfunction. Psychopathology is defined as persistent failure to move toward one's goals, due to failure to generate effective new goals, interpretations, or strategies when existing ones prove unsuccessful. We argue that adopting a cybernetic theory to replace conceptualizations of psychopathology as statistical deviance or brain disease would facilitate improvements in measurement, diagnosis, prevention, and treatment of psychopathology.
\end{abstract}

Keywords: psychopathology, mental disorder, cybernetics, statistical deviance, brain disease 
General Scientific Summary: In our new theory of psychopathology, to be considered mentally ill people must be persistently unable to move toward their important life goals, due to failure to generate effective new goals, interpretations, or strategies when existing ones prove unsuccessful. This theory invalidates the typical assumptions that psychopathology is necessarily a function of having unusual characteristics and that mental illness is really disease of the brain. 
Cybernetic Psychopathology 4

\section{A cybernetic perspective on the nature of psychopathology: Transcending conceptions of mental illness as statistical deviance and brain disease}

In the scientific literature on mental illness, the question of what exactly mental illness is comes up surprisingly infrequently. This is probably because psychiatry and clinical psychology, and indeed medicine in general, operate at the intersection of science and practice. Because of the need to treat, medicine cannot wait for well-specified and thoroughly elaborated scientific theories that would explain the problems it faces. Over time, the science of medicine advances and in some areas catches up with practice, leading to clearer theories of the etiology and processes of disease, as well as to improved interventions. In other areas, it lags, and in those areas, theory tends to be focused on official diagnostic entities inherited from old attempts at medical taxonomy, even when those are clearly scientifically inadequate. Psychiatry is such an area, with the result that there is much written about the nature of schizophrenia or borderline personality disorder or post traumatic stress disorder, but comparatively little about the nature of mental illness itself.

Another consequence of the paucity of good explanations in mental health research is that the few general theories of mental illness that exist are not necessarily influential on the research and theory that surrounds mainstream psychiatry and psychology. The prime example here is Wakefield's (1992a, 1992b) harmful dysfunction theory of mental disorder. This theory currently dominates conversations about the nature of mental illness as such, but we would argue that it has little influence on nosological or etiological research or on the many theories of specific disorders. 
Wakefield's theory is what is known as a hybrid theory, in that it combines elements of a naturalistic account (specifying disorder as an objective matter of fact) with elements of a valuesbased account (specifying disorder as a cultural construction based on sociopolitical concerns). Specifically, Wakefield (2007, p. 149) states that "a condition is a disorder if it is negatively valued ('harmful') and it is in fact due to a failure of some internal mechanism to perform a function for which it was biologically designed (i.e., naturally selected)," and he further defines "harmful" as "judged negative by sociocultural standards." The naturalistic component of this theory invokes evolutionary dysfunction, which entails that explanation of any specific disorder requires knowledge of the effects on fitness that shaped the evolution of the mechanism(s) responsible for the disorder. This requirement raises a very high hurdle for scientific theory (Bolton, 2008), potentially explaining the paradoxical lack of influence of Wakefield's theory on research on mental disorders despite its great influence on accounts of mental disorder as such.

We recently proposed a novel theory of mental illness involving cybernetic dysfunction, failure of the person to make progress toward important psychological goals (DeYoung \& Krueger, 2018a), which we believe provides a better foundation for scientific theories of psychopathology, as well as clinical practice, than Wakefield's or any other extant theory. (In our theory, as explained below, we define "psychopathology" distinctly from "mental disorder," but the other perspectives we are reviewing here tend to use them interchangeably.) In presenting our theory, we took pains to distinguish it from the harmful dysfunction theory, primarily because the difference between evolutionary and cybernetic dysfunction is crucial for our theory, ${ }^{1}$ but also simply because of the importance of Wakefield's theory in the literature on defining mental illness. In the present article, we wish to distinguish our theory more thoroughly from two perspectives that we perceive to be much more influential than Wakefield's, at least 
implicitly, in mainstream mental health research. These are conceptions of mental illness as statistical deviance and as brain disease.

Statistical deviance theories of mental (and physical) illness have been around for some time (e.g., Boorse, 1977; Cohen, 1955; Scadding, 1967). Their most general form, asserting that any attribute becomes pathological when it deviates too far from a population norm, is easy to discredit, as it would render high levels of talent, ability, or other beneficial qualities a disorder (Wakefield, 1992a). Hence, all potentially viable versions of the theory require deviation in a disadvantageous or dysfunctional direction, which then requires an additional definition of disadvantage or dysfunction. Probably the most influential such theory is Boorse's (1977, 2011, 2014) biostatistical theory (presented as a theory of health and disease generally, rather than mental illness specifically), which specifies that disorder consists of negative deviation from the population norm (stratified by age and sex) in any mechanism's facilitation, in a currently species-typical manner, of survival or reproduction. Some of the deficiencies of this theory have to do with its choice of survival and reproduction as the two crucial functional outcomes for health, despite explicitly rejecting an evolutionary account of dysfunction (Boorse, 2011, 2014; DeYoung \& Krueger, 2018a; Wakefield, 1992a), but this component of the theory is not widely adopted in research on psychopathology. Of more interest here are the problems that arise from using statistical deviance as a criterion for disorder, and this approach is widespread in mainstream mental health research, even when it does not explicitly draw on any philosophical account like Boorse's and even when statistical deviance is not explicitly mentioned in defining disorder.

The ubiquity of the statistical deviance approach is evident in a common label for the field itself (indeed, the former name of the journal in which this article appears): "Abnormal 
Psychology." Researchers in the field tend to use "abnormal" synonymously with "pathological," but most literally it just means "away from the norm" or "unusual," and the literal meaning does in fact reflect the way most research identifies psychopathology. Our argument is not that most research explicitly adopts a definition based on statistical deviance, but rather that the assumption that statistical deviance is the primary criterion for psychopathology is inherent to the way measures of psychopathology (including diagnoses) are typically created and interpreted.

Probably the most important current example of implicit reliance on statistical deviance is the American Psychiatric Association's (APA) Diagnostic and Statistical Manual, Fifth Edition (DSM-5), which defines mental disorder generally as "a syndrome characterized by clinically significant disturbance in an individual's cognition, emotion regulation, or behavior that reflects a dysfunction in the psychological, biological, or developmental processes underlying mental functioning" (APA; 2013, p. 20). The largest problem with this definition is that it does not define "dysfunction," which has various meanings (DeYoung \& Krueger, 2018a; Stein et al., 2010). However, we can also consider the assumptions involved in DSM-5's diagnoses of individual mental disorders (which are, after all, far more influential on research than the vague general definition). Although the general definition does not explicitly mention statistical deviance, diagnostic criteria for most individual disorders require a certain number of symptoms to be present, often more than half (the exact number being seldom, if ever, empirically justified). Most people in the general population typically have very few symptoms of any given disorder, and so the diagnostic criteria require deviation from the normal range of symptoms as the central feature of each disorder (throughout, we use the word "symptom" broadly to refer to externally observable signs as well as subjective experiences). 
Recent alternatives to the $D S M-5$ for the purpose of characterizing features of psychopathology, such as National Institute of Mental Health's (NIMH) Research Domain Criteria (RDoC; Insel et al., 2010) or the Hierarchical Taxonomy of Psychopathology (HiTOP; Krueger et al., 2018), have shifted to dimensional approaches in order to address the shortcomings of categorical diagnoses. This shift toward dimensional approaches (which in many ways merely systematize the dimensional approach already taken for decades in much clinical psychological research) is certainly necessary, but in no way does it eliminate the problems with relying on statistical deviance to identify psychopathology. Although dimensional approaches do not impose arbitrary thresholds to create disorder categories, researchers using them nonetheless frequently assume that the number or intensity of symptoms (or whatever other clinically relevant dimension is being considered) is equivalent to the severity of psychopathology. In research using either case-control designs or continuous symptom dimensions, differences in psychological or neural function between diagnosed and control groups, or between those with higher and lower scores on some symptom dimension, are often asserted to indicate deficiency or dysfunction in the relevant psychological or neural mechanisms, without any clear evidence that such is the case beyond the fact that they were associated with symptom scores or membership in a clinical group.

Why should researchers not assume that any elevation in the number or intensity of anything considered to be a symptom of mental disorder is indeed indicative of the presence of psychopathology? There are two general problems with this assumption. The first is the difficulty of deciding how far from the norm a deviation on any given dimension must be before being deemed pathological. The second is the fact that some people with high scores on almost any symptom dimension do not have the suffering or impairment that is expected to accompany 
mental illness, and without which it is difficult to claim that the person is "ill" (e.g., Clark \& Ro, 2014; Linscott \& van Os, 2013).

The first problem is widely recognized in the literature on defining mental disorder. Boorse $(1977,2014)$, for example, acknowledges that what distance from the norm of functioning should constitute pathology for any mechanism is "arbitrary" or "conventional" (an admission that undercuts his claim to have developed a purely naturalistic theory, since it entails that determining pathology involves a value judgment about how large a deviation matters). Nor can the problem be avoided by specifying that any deviation from the norm in a dysfunctional direction is at least slightly pathological, because nearly every individual will vary at least slightly from the norm (in both directions) on vastly many functionally relevant dimensions, and no sensible account of health renders nearly everyone pathological. In practice, this issue is simply ignored in most dimensional research and resolved by fiat, without justification, in research based on conventional diagnoses.

The second problem stems from the fact that, although the word "symptom" is often taken to refer to something inherently indicative of the presence of disorder, this is not an appropriate reading of its typical usage in mental health research because many symptoms used to identify psychopathology can be found in many healthy people. The DSM-5 acknowledges that "it has not been possible to completely separate normal and pathological symptom expressions contained in diagnostic criteria" (APA, 2013, p. 21). What could a "normal symptom expression" indicate? We will argue that, if persistent, it indicates a feature of personality or, if confined to a brief episode, a merely unusual behavioral or experiential state. At any rate, the prevalence of such "symptoms" in the healthy population explains why most DSM-5 diagnoses 
include as a criterion that either distress or social or occupational impairment must be present along with meeting the symptom criteria.

One might think, therefore, that the DSM-5 diagnostic system was based on the premise that impairment is one of two true markers of psychopathology (with the other being distress), but no; in fact, its authors are apologetic about the necessity of including impairment as a criterion despite "substantial efforts ... to separate the concepts of mental disorder and disability (impairment in social, occupational, or other important areas of functioning)" (APA, 2013, p. 21). The impairment criterion is seen as a stopgap on the way to developing better methods for identifying mental disorder based on "clear biological markers or clinically useful measurements of severity" (APA, 2013, p. 21). (The invocation of "biological markers" provides an example of the tendency to treat psychopathology as brain disease; an issue to which we will return after describing our theory in more detail.) Thus, DSM-5 recognizes that statistical deviance models tend to founder on the problem that many healthy people are statistically deviant on the same dimensions that are often associated with psychopathology and acknowledges that this problem is yet to be solved.

Could the solution to this problem be to weed out anything that could be nonpathological from our lists of symptoms? The example of hallucinations and delusions, cardinal symptoms of the psychotic disorders that are widely recognized as among the most severe forms of psychopathology, serves to illustrate the impossibility of this solution (Linscott \& van Os, 2013). Imagine someone who frequently hears disembodied voices and believes that he is communicating with spirits of the dead. These are clearly hallucinations and delusions, and even without knowing anything else about the case, one might be tempted to think that a diagnosis of schizophrenia or other psychotic disorder was likely. Now imagine, however, that this person is a 
successful and happy psychic, with a flourishing business and a robust social network of friends who either humor, share, or respectfully disagree with his belief system. Given the lack of both impairment and distress, DSM-5 would not consider this person disordered, but it is hard to imagine removing hallucinations and delusions from lists of psychiatric symptoms. This is not a fanciful example, as a recent study of "clairaudient psychics who receive daily auditory messages" "from other realms" makes clear (Powers et al., 2017). These psychics were a healthy, nonclinical sample, who were compared to psychotic patients who also have daily auditory hallucinations. Not surprisingly, the patient group showed much higher levels of a variety of symptoms than the psychics, but the two groups were not significantly different on standard clinical measures of hallucinations. Even after considering this example, one might suspect there must be at least a few rare dimensions of psychological variation on which extremity is necessarily indicative of psychopathology. Indeed, we believe there are, but those are precisely dimensions in which cybernetic dysfunction is explicitly specified, in the manner that our theory describes.

\section{The Cybernetic Dysfunction Theory}

Thus far, we have not made a clear distinction between the terms "mental disorder," "psychopathology," and "mental illness," because the perspectives we have been reviewing have not typically made any systematic distinction among them. In our theory, however, we make an explicit distinction between "mental disorder," which we reserve for official diagnostic entities, such as those of the DSM (which we think those should be replaced), and "psychopathology," which we reserve for the naturalistic component of our theory - that is, the objective presence of psychological dysfunction. In the present article, we use "mental illness" more broadly to cover all perspectives on mental health problems. 
Conceptually separating psychopathology from mental disorder allows our theory to resolve the problems faced by statistical deviance models. We specify that the presence versus absence of psychopathology is a binary variable having nothing to do with statistical deviance, and that its severity, once present, is a continuous variable. Both presence and severity of psychopathology we take to be matters of objective fact, despite difficulties in assessment that we will discuss below, and thus our theory of psychopathology is purely naturalistic. Our theory of mental disorder, in contrast, is hybrid because we argue that criteria for a diagnosis of mental disorder should include both the presence of psychopathology and an additional value judgment about what level of severity is worthy of treatment. Thus, our definition of mental disorder allows for considerations of statistical deviance in the value judgments that establish diagnostic thresholds. Such judgments must be reached through processes of sociopolitical negotiation among various stakeholders, including the organizations that control official diagnostic systems. There is no objectively correct single answer to the question of what level of severity of psychopathology warrants a diagnosis of mental disorder.

Our theory does not attempt to specify the exact level of psychopathology that warrants a diagnosis, not only because this requires extra-scientific negotiations that should be informed by policy research, but also because the same level of psychopathology might warrant a different diagnostic status under different circumstances, such as different symptom profiles or demographic groups (DeYoung \& Krueger, 2018b). Further, our theory is amenable to different diagnoses across gradations of severity for similar problems. In these considerations, our theory corresponds well to ways in which much of physiological medicine already proceeds, for example in identifying different levels of blood pressure to designate as hypertension vs. prehypertension or considering demographic variables in medical evaluation. 
Throughout the rest of this article we focus on psychopathology, rather than mental disorder, as the proper target for scientific research. The crucial question is how psychopathology can be identified without relying on statistical deviance. We define psychopathology as persistent failure to move toward one's goals, due to failure to generate effective new goals, interpretations, or strategies when existing ones prove unsuccessful. Due to space limitations, we will not review all the naunces of our theory and the relevant principles of cybernetics, and interested readers should see our previous treatments (DeYoung \& Krueger, 2018a, 2018b) or refer to our online supplement addressing frequently asked questions.

Cybernetics is the study of the principles governing goal-directed systems that selfregulate via feedback (Wiener, 1948; Carver \& Scheier, 1998). Cybernetic systems minimally require three elements (although complex systems like human beings contain other forms of control mechanism as well): (1) a goal or set of goals physically instantiated in the system as values (or ranges of values) of controlled variables (and these goals may change over time); (2) an indication of the current state of the controlled variable, which is compared to the goal state via feedback; and (3) an operator or set of operators that can be engaged to bring the current state of the system toward the goal state. The term "goal" has a much more general meaning in cybernetics than it does in psychology, and the goals referenced in our definition of psychopathology are not just any goals that are under cybernetic control in the human organism (which would include lower-level physiological processes like the control of blood pressure by the kidneys), but specifically psychological goals.

Further, what we mean by "psychological goals," although only a subset of cybernetic goals, is still broader than what many psychologists mean by "goals." Whereas many psychologists limit goals to conscious, detailed representations of a desired future with an 
accompanying commitment to action (e.g., Elliot \& Fryer, 2008), in our theory, a psychological goal can be unconscious and it can also have no commitment to action if it is low enough in priority. What psychologists refer to as "motives" and "needs" are also psychological goals in our usage. Psychological goals in this broad sense are what we mean by "goals" in what follows.

Psychopathology requires failure to move toward important goals, those that have priority for the person in day-to-day life and over the long term. The more goals that are disrupted, and the more important those goals are, the more severe the psychopathology. Disruption or thwarting of goals, especially when those goals include basic needs, is the primary cause of human distress, and avoiding suffering is an important goal for most people. Crucially, however, it is not just any failure of goal pursuit that indicates psychopathology, or else anyone facing vicissitudes that temporarily disrupted their goals would be deemed pathological. A cybernetic system is not dysfunctional just because it is temporarily failing to make progress toward its goal, as long as the appropriate processes are engaged to correct its course. This is the reason for the second half of our definition of psychopathology.

A person's goals, interpretations, and strategies for pursuing their goals are equivalent to the three basic cybernetic elements, with interpretations of self and world being the human version of the system's representation of the current state. Human representations of the present are based on past experience and so our interpretations include our memories of the past; they also include predictions about what is likely in the future given the present situation (as distinct from our goals, which are what we desire for the future, regardless of what is likely). Unlike the simplest cybernetic systems, which cannot change their elements, human beings can develop new goals, interpretations, and strategies. Such adaptation is accomplished through processes of exploration and learning that are themselves goal-directed and hence cybernetic, as discovering 
new information and figuring out new behavioral strategies are goals in and of themselves (DeYoung \& Krueger, 2018b).

Inasmuch as learned goals, interpretations, and strategies are persistent, they become characteristic adaptations, a component of people's personalities (DeYoung, 2015). When existing characteristic adaptations are not sufficient to allow people to make progress toward their goals, people must adapt, developing new characteristic adaptations that will allow them to resume progress toward their goals. This process of adaptation can include not only developing new strategies for pursuing existing goals or changing maladaptive interpretations of oneself or external events, but also abandoning or reprioritizing existing goals and adopting new goals. In psychopathology, the process of adaptation fails, and the person is unable to develop characteristic adaptations that are cybernetically effective.

Our cybernetic theory of psychopathology has two major components, which center around the two categories of personality construct identified by Cybernetic Big Five Theory (CB5T), personality traits and characteristic adaptations (DeYoung, 2015). Whereas characteristic adaptations, described above, are always learned and must be specified in relation to an individual's particular life circumstances, personality traits are dispositions toward patterns of behavior, motivation, emotion, and cognition that stem from parameters of evolved cybernetic mechanisms present in every intact human brain. These are the general mechanisms that allow people to carry out any specific goal they may have, by energizing action, prioritizing subgoals, detecting errors, etc. The parameters of these mechanisms may be adjusted to some extent by experience (personality traits change over the lifespan, partly in response to specific life events; Bleidorn, Hopwood, \& Lucas, 2018), but some level of the trait exists for everyone, which is not the case for characteristic adaptations. Any construct that is a personality trait should be 
applicable to describing differences between people in any culture at any time in human history. Because of the breadth of CB5T's definition of "personality trait," most cognitive abilities (e.g., intelligence) are personality traits and so are many persistent symptoms of psychopathology.

The two major components of our theory of psychopathology are (1) a definition of psychopathology in terms of the failure of characteristic adaptations (as described above), and (2) a description of psychological and neural mechanisms responsible for the major dimensions of features of psychopathology, which are largely equivalent to major personality traits, including the Big Five (DeYoung \& Krueger, 2018a; Widiger et al., 2019). In the present article, we will not review the second component of the theory; what is of importance here is just our assertion that extreme levels on these dimensions are not inherently pathological in and of themselves. Rather each dimension constitutes a different form of risk for psychopathology, based either on a person's personality (to the degree that extreme levels on the dimensions in question are longstanding) or on temporary fluctuations away from the person's typical levels into more extreme levels.

As noted above, one reason that deviation from the norm fails as a criterion for psychopathology is that, in virtually every psychological dimension, variation is the norm and healthy people with extreme levels can be found. Only when deviation from psychological norms leads to cybernetic dysfunction is psychopathology present. This entails that people with extreme trait levels on dimensions of risk for psychopathology can be healthy as long as they are able to develop characteristic adaptations that either complement or compensate for their extreme trait levels, such that they are able to pursue their own goals in life effectively. Further, people without extremity on any of the major dimensions of risk can have psychopathology if they are, for whatever reason, unable to pursue their goals effectively and unable to develop new 
characteristic adaptations that would allow them to resume effective goal pursuit. In short, extremity on trait or symptom dimensions is neither necessary nor sufficient for psychopathology, whereas persistent failure of characteristic adaptations is both necessary and sufficient.

\section{Assessing Psychopathology}

Our theory has a number of important implications for the assessment of psychopathology. Most importantly, it suggests that psychopathology should be assessed in two stages, again corresponding to the difference between characteristic adaptations and trait or symptom dimensions. The first task in any assessment must be to determine (a) whether the person is persistently unable to make progress toward their goals (considering the entirety of their collection of goals, especially paying attention to basic needs and motives of which the person may not be fully aware), or (b), if they have only recently had a serious setback in goal progress, whether they seem to be making progress in adaptation toward finding new goals, interpretations, and/or strategies that are likely to allow them to resume effective goal pursuit. Only after identifying that psychopathology is present does one need to proceed to the second stage, which involves characterizing the features of psychopathology through a thorough review of the major dimensions of psychopathology and their various subdimensions.

Note that this is roughly the opposite sequence from the process involved in making most $D S M-5$ diagnoses, in which one first assesses specific symptoms and only secondarily considers whether impairment is present. In our theory, unlike the $D S M-5$, there is no need to apologize for the use of impairment as a criterion, given that cybernetic dysfunction is a sensible way to interpret "impairment." In fact, rather than being a stopgap on the way to better methods of assessment, properly assessing impairment, as cybernetic dysfunction, should be the foundation 
of clinical assessment. Some might think that "social and occupational impairment," as framed by the $D S M-5$, could be identifiable by the same criteria for everyone, but we stress that dysfunction is always relative to the individual's own goals, both conscious and unconscious. Many of those goals are likely to be social and occupational, of course, but the person's own idiosyncratic collection of goals must be assessed.

We mentioned above that there might exist dimensions of psychological variation in which extremity was inherently indicative of psychopathology. This can occur when persistent inability to achieve one's goals is specified as part of the dimension itself, which sometimes occurs in descriptions of symptoms. If someone scores high on a measure indicating that they are unable to meet their needs or progress toward important goals in life, for whatever reason, then this assessment is essentially a crude version of what we envision as necessary for identifying psychopathology. However, the fact that people may not be conscious of some of their own goals or the priority they place on certain goals (for example, people who believe they have little need for social affiliation may be mistaken) makes good assessment of psychopathology more difficult than what can easily be accomplished with a standardized questionnaire. Each person's set of goals is different, and a thorough clinical interview is probably necessary to achieve a good understanding of someone's dysfunction and its severity.

One part of DSM-5 to which our recommended strategy of assessment bears some resemblance is the Alternative DSM-5 Model for Personality Disorders, which is not currently part of the official diagnostic system but appears in Section III: Emerging Measures and Models. In this model, the first criterion for a diagnosis is "moderate or greater impairment in personality (self/interpersonal) functioning," and the second is "one or more pathological personality traits" (notably assessed in terms of "elevation" potentially in relation to "population norms"). Certainly 
there are some differences from our theory here; we do not agree that extremity on any of the personality traits listed is inherently pathological, and we do not think the four elements of personality functioning described in the model are sufficiently focused on the individual's goal pursuit, because they also include dimensions of risk that are simply additional personality traits (e.g. empathy). Nonetheless, the basic framework is similar: first identify the presence of psychopathology, then characterize it with reference to a set of dimensions describing specific symptoms.

The element of personality functioning described by the alternative model as "selfdirection" has strong parallels to our concept of cybernetic dysfunction, with severe impairment characterized as, "Has difficulty establishing and/or achieving personal goals.” Further, one of the additional criteria for personality disorder (pervasiveness) requires that "individuals are unable to modify their thinking or behavior, even in the face of evidence that their approach is not working," which corresponds reasonably well to the second half of our definition of psychopathology. Thus, parallels to the kind of system we propose already exist in the field, although our theory is applicable to all psychopathology, not just to what are traditionally labeled personality disorders (Clark, 2007). Further, we believe that our system corresponds reasonably well to the way in which many front-line clinicians actually proceed, being more concerned with the concrete details of their patients' problems than with official diagnostic criteria. A diagnostic system in line with our theory would, therefore, be better aligned not only with the science of psychopathology but also with clinical practice.

\section{Why Psychopathology is not Brain Disease and What That Means for Intervention}

We have stressed that extremity on major dimensions of psychopathology, even when those are conceived as "symptoms," should not be considered necessary or sufficient for 
psychopathology. This does not mean, however, that we view understanding these dimensions as unimportant. As dimensions of risk, they are frequently crucial contributing causes of cybernetic dysfunction. When mechanisms within the cybernetic system operate in extreme and unusual ways, they tend to make it harder for the system to function coherently as a whole to generate effective goal pursuit. Thus, although extreme traits (reflecting persistently extreme functional parameters) are neither necessary nor sufficient for psychopathology, they are important to identify in psychopathology for the purposes of understanding etiology and directing treatment. Additionally, as risk factors, they will be important to identify for the purpose of prevention prior to the onset of psychopathology. In some cases, extreme levels of these symptom dimensions can be caused by psychopathology. For example, high levels of Neuroticism or Negative Affect are a typical outcome of cybernetic dysfunction, and this is the dimension most affected by various forms of therapy (DeYoung \& Krueger, 2018a; Roberts et al., 2017).

Given that the major trait dimensions are important for understanding psychopathology and that our theory also indicates that these dimensions reflect the operations of identifiable neural systems, why are we opposed to viewing psychopathology as brain disease? Again, the main reason is that unusual patterns of brain function, though they are sometimes contributing causes of psychopathology, are typically neither necessary nor sufficient for psychopathology. We are skeptical, therefore, that biomarkers could ever replace clinical interviewing for the purpose of diagnosis. Any such biomarker would need to indicate with reasonable certainty that the person was persistently unable to pursue their important goals, and this is unlikely for all the same reasons that statistical deviation on psychological dimensions generally cannot indicate psychopathology. Following identification of cybernetic dysfunction through clinical interview, it would be reasonable to use biological assessments to identify potential contributing causes to 
psychopathology, but this must not be mistaken for identifying psychopathology itself. Thus, we are skeptical about the viability of "a neuroscience-based approach to psychiatric classification" (Insel et al., 2010, p. 748), when that approach is intended to identify the presence of psychopathology, rather than simply to aid in understanding the possible causes and consequences of psychopathology identified through other means.

The creators of RDoC were explicit that "the RDoC framework conceptualizes mental illnesses as brain disorders" (Insel et al., 2010, p. 749). Similarly, the National Institute on Drug Abuse (2018) defines addiction as "a chronic, relapsing brain disease." The DSM-5 does not endorse the idea that mental disorders are necessarily disorders of the brain, but nonetheless a wish for biological diagnostic criteria is evident, both in the inclusion of biological dysfunction in the general definition of mental disorder and in the stated desire for "clear biological markers" that might obviate the need for social and occupational impairment as a criterion. The idea that mental illness is best conceived as brain disease is pervasive in the current medical zeitgeist (Borsboom et al., 2019). ${ }^{2}$ Nonetheless, it is misguided and can have unfortunate consequences.

To be clear, there is much about the aims of RDoC that we value (Krueger \& DeYoung, 2016). First, dimensional approaches to psychopathology are a necessary replacement for empirically unfounded categorical nosologies. Second, all mental phenomena are carried out by neurobiological processes, and we can gain valuable information about psychopathology through neuroscience (indeed, both of us conduct research on the neural correlates of both personality and features of psychopathology). Third, public understanding that neurobiological factors contribute to mental illness helps to reduce stigma. Similarly, we value the degree to which scientific knowledge about the neural processes of addiction has helped the public take addiction seriously as psychopathology rather than as moral failure. Nonetheless, we believe that defining 
psychopathology as brain disease leads the field away from research that could be most efficacious for developing interventions to improve mental health, given the different points at which intervention is possible within the human cybernetic system.

[Insert Figure 1 about here.]

Figure 1 shows the causal model adopted by our theory, in which variations in cybernetic mechanisms produce the regularities in behavior and experience described as personality traits or persistent symptom dimensions, which then influence the characteristic adaptations that people develop. Two potential points of intervention in the system are identified, one through biological interventions, directly acting on the cybernetic mechanisms that enable the system to carry out goal-directed behavior generally, and another through behavioral and talk-therapy interventions that help people to understand and change their specific characteristic adaptations. (Another important intervention point, not indicated in the figure, is the environment, where various threats to public health may be controlled or eliminated, but we focus here on interventions targeting individuals.) Because our theory defines psychopathology in terms of failure of characteristic adaptations, behavioral and talk therapies act most directly on the problem, and biological interventions are effective only inasmuch as the changes they make to cybernetic mechanisms subsequently allow people to develop and maintain effective characteristic adaptations.

Whereas "[t]he primary focus for RDoC is on neural circuitry" (Insel et al., 2010, p. 749), we believe that the primary focus of research on psychopathology should be on cybernetic dysfunction, with an emphasis on identifying interventions that eliminate such dysfunction by fostering effective characteristic adaptations. Because characteristic adaptations are specific memories, they cannot be directly and specifically adjusted through pharmacological 
interventions, even if such interventions sometimes change the general functioning of the brain in such a way as to facilitate adjustment of characteristic adaptations. Remarkably, even for altering levels of broad personality traits, behavioral and talk therapies appear to be more effective than current pharmacological interventions (Roberts et al., 2017), which is probably because the neural systems underlying any given trait are complex, and our understanding of them is still limited, making it difficult to target the right neurobiological parameters.

The NIMH has suggested that funded clinical trials must demonstrate "not only that an intervention ameliorated a symptom, but that it had a demonstrable effect on a target, such as a neural pathway implicated in the disorder or a key cognitive operation" (Insel, 2014). Enforcing such a requirement would be a serious mistake because abnormal function at the level of such target mechanisms (encompassed by the "Cybernetic Mechanisms" box in Figure 1) is not necessary for psychopathology, and improvement in psychopathology can typically occur only with change in characteristic adaptations. Because our theory specifies that psychopathology requires failure of characteristic adaptations, and characteristic adaptations are by definition learned, the brain itself may be in no way diseased and yet have learned a set of characteristic (mal)adaptations that prevent the mentally ill person from pursuing their important goals effectively. The most important outcome for any clinical trial in mental health research should be the degree to which people regain cybernetic function - their capacity to pursue their own individual collection of goals.

Again, we are not advocating for the abandonment of clinical neuroscience research. The major dimensions of psychopathology reflect neural parameters that may sometimes be effective targets of intervention (DeYoung \& Krueger, 2018a). Further, in some forms of psychopathology, such as Alzheimer's disease, psychological dysfunction tracks closely with 
what appear to be clearly pathophysiological neurobiological processes (Fernández-Cabello et al., 2020; Jack et al., 2016), and here biological treatments are almost certainly necessary. Nonetheless, in our theory, pathologies like Alzheimer's become psychopathologies, as opposed to merely neurological problems, only when patients cease to be able to pursue their important goals and to adjust their characteristic adaptations to deal effectively with their condition.

There are other forms of psychopathology, such as severe mania, in which some risky aspect of neural functioning — even if not neurologically pathological, strictly speaking —is so extreme that it is unlikely to be treatable exclusively through the adjustment of characteristic adaptations. In these cases, pharmacological interventions are certainly appropriate. We do, however, have a somewhat different perspective on the course of such psychopathology than is typical in the field. Someone with a tendency toward mania that has been well controlled by lithium for some extended period of time (for example) is not mentally ill and does not have any current psychopathology, despite the fact that ceasing to take lithium might well lead to a relapse of psychopathology. Some people are prescribed drugs in an ongoing way to prevent them from becoming mentally ill, and this use of pharmaceuticals can be appropriate, but our theory indicates that those people are not psychopathological as long as the risk is so well controlled that they do not have any cybernetic dysfunction.

\section{Conclusion}

Our cybernetic theory of psychopathology provides an alternative to approaches that are evident in much research on the assessment, etiology, prevention, and treatment of psychopathology. Many common approaches assume, at least implicitly, that deviation from the norm in various dimensions of psychological or neural function is necessary for psychopathology, and many also assume that psychopathology is fundamentally a disease of the 
brain. Hopefully, our explication of the problems with these assumptions will encourage research that distinguishes between the presence of psychopathology, defined as cybernetic dysfunction, and the various common features of psychopathology that are described by dimensional models. (Research based on the categorical diagnoses of the DSM should be avoided entirely.) Use of such dimensional models is necessary but requires recognition that extreme levels on symptom dimensions indicate risk for or consequences of psychopathology, rather than being inherently pathological in and of themselves. Hence, researchers should be careful not to claim that associations with any given symptom dimension indicate pathology in psychological or neural mechanisms.

Further, although research using dimensional models can facilitate clinical neuroscience (Latzman et al., 2020), a primary focus on understanding the neural correlates of various dimensions of psychopathology is not likely to provide the fastest or most effective improvement to our capacity for prevention and treatment of mental illness. Instead, clinical intervention research should increase its focus on methods for helping people to change their goals, interpretations of self and world (including emotional reactions), and strategies for achieving their goals. These things are often more directly and efficiently changed by behavioral or talk therapies than by biological interventions. We do not want to see the end of neuroscience research on any particular clinical phenomena, and we are confident that biological interventions will always have a place in the treatment of some forms of psychopathology. Nonetheless, ultimately, psychopathology can be overcome only by helping people to set aside characteristic maladaptations that prevent them from pursuing their goals effectively and to adopt new adaptations that become persistent elements of their personalities. 


\section{References}

Allen, T. A., \& DeYoung, C. G. (2017). Personality neuroscience and the Five Factor Model. In T. A. Widiger (Ed.). Oxford handbook of the Five Factor Model (pp. 319-349). New York: Oxford University Press.

Allen, T. A., DeYoung, C. G., Bagby, M. B., Pollock, B. G., \& Quilty, L. C. (2020). A hierarchical integration of normal and abnormal personality dimensions: Structure and predictive validity in a heterogeneous sample of psychiatric outpatients. Assessment, 27, $643-656$.

American Psychiatric Association (2013). Diagnostic and statistical manual of mental disorders, fifth edition. Arlington, VA: American Psychiatric Association.

Ashby, W. R. (1956). An introduction to cybernetics. London, UK: Chapman and Hall.

Bergner, R. M. (1997). What is psychopathology? And so what? Clinical Psychology: Science and Practice, 4(3), 235-248.

Bleidorn, W., Hopwood, C. J., \& Lucas, R. E. (2018). Life events and personality trait change. Journal of Personality, 86, 83-96.

Bolton, D. (2008). What is mental disorder?: An essay in philosophy, science, and values. New York: Oxford University Press.

Boorse, C. (1977). Health as a theoretical concept. Philosophy of science, 44(4), 542-573.

Boorse, C. (2011). Concepts of health and disease. In F. Gifford (Ed.), Handbook of the Philosophy of Science, vol. 16: Philosophy of Medicine (pp. 13-64). New York: Elsevier.

Boorse, C. (2014). A second rebuttal on health. Journal of Medicine and Philosophy, 39, 683724.

Borsboom, D. (2017). A network theory of mental disorders. World Psychiatry, 16, 5-13. 
Borsboom, D., Cramer, A. O., \& Kalis, A. (2019). Brain disorders? Not really: Why network structures block reductionism in psychopathology research. Behavioral and Brain Sciences, 42, e2, 1-63.

Bringmann, L. F., \& Eronen, M. I. (2018). Don't blame the model: Reconsidering the network approach to psychopathology. Psychological Review, 125(4), 606-615.

Carragher, N., Krueger, R. F., Eaton, N. R., Markon, K. E., Keyes, K. M., Blanco, C., ... Hasin, D. S. (2014). ADHD and the externalizing spectrum: Direct comparison of categorical, continuous, and hybrid models of liability in a nationally representative sample. Social Psychiatry and Psychiatric Epidemiology, 49, 1307-1317.

Carver, C., \& Scheier, M. (1998). On the self-regulation of behavior. New York: Cambridge University Press.

Clark, L. A. (2007). Assessment and diagnosis of personality disorder: Perennial issues and an emerging reconceptualization. Annual Review of Psychology, 58, 227-257.

Clark, L. A., \& Ro, E. (2014). Three-pronged assessment and diagnosis of personality disorder and its consequences: Personality functioning, pathological traits, and psychosocial disability. Personality Disorders: Theory, Research, and Treatment, 5, 55-69.

Cohen, H. (1955). The evolution of the concept of disease. Proceedings of the Royal Society of Medicine, 48, 155-160.

DeYoung, C. G. (2015). Cybernetic Big Five Theory. Journal of Research in Personality, 56, $33-58$.

DeYoung, C. G., Carey, B. E., Krueger, B. F., \& Ross, S. R. (2016). Ten aspects of the Big Five in the Personality Inventory for DSM-5. Personality Disorders: Theory, Research, and Treatment, 7, 113-123. 
DeYoung, C. G., \& Krueger, R. F. (2018a). A cybernetic theory of psychopathology. Psychological Inquiry, 29, 117-138.

DeYoung, C. G., \& Krueger, R. F. (2018b). Understanding psychopathology: Cybernetics and psychology on the boundary between order and chaos. Psychological Inquiry, 29, 165174.

DeYoung, C. G. \& Rueter, A. R. (2016). Impulsivity as a personality trait. In K. D. Vohs \& R. F. Baumeister (Eds.). Handbook of Self-Regulation: Research, Theory, and Applications (Third edition, pp. 345-363). New York: Guilford Press.

DeYoung, C. G., \& Weisberg, Y. J. (2019). Cybernetic approaches to personality and social behavior. In M. Snyder \& K. Deaux (Eds). Oxford handbook of personality and social psychology, Second edition (387-414). New York: Oxford University Press.

Elliot, A. J., \& Fryer, J. W. (2008). The goal construct in psychology. In J. Y. Shah \& W. L. Gardner (Eds.), Handbook of motivation science (pp. 235-250). New York: Guilford.

Fernández-Cabello, S., Kronbichler, M., Van Dijk, K. R., Goodman, J. A., Spreng, R. N., Schmitz, T. W., \& Alzheimer's Disease Neuroimaging Initiative (2020). Basal forebrain volume reliably predicts the cortical spread of Alzheimer's degeneration. Brain, 143, 993-1009.

Gray, J. A. (2004). Consciousness: Creeping up on the hard problem. New York: Oxford University Press.

Gray, J. A., \& McNaughton, N. (2000). The neuropsychology of anxiety: An enquiry into the function of the septo-hippocampal system. New York, NY: Oxford University Press. 
Haslam, N., McGrath, M. J., Viechtbauer, W., \& Kuppens, P. (2020). Dimensions over categories: a meta-analysis of taxometric research. Psychological Medicine. DOI: https://doi.org/10.1017/S003329172000183X.

Heyman, G. M. (2013). Quitting drugs: Quantitative and qualitative features. Annual Review of Clinical Psychology, 9, 29-59.

Insel, T. (2014). Post by former NIMH Director Thomas Insel: A new approach to clinical trials. https://www.nimh.nih.gov/about/directors/thomas-insel/blog/2014/a-new-approach-toclinical-trials.shtml (Retrieved April 2, 2020).

Insel, T., Cuthbert, B., Garvey, M., Heinssen, R., Pine, D. S., Quinn, K., ... \& Wang, P. (2010). Research domain criteria (RDoC): toward a new classification framework for research on mental disorders. The American journal of psychiatry, 167, 748-751.

Jack, C. R., Bennett, D. A., Blennow, K., Carrillo, M. C., Feldman, H. H., Frisoni, G. B., ... \& Petersen, R. C. (2016). A/T/N: an unbiased descriptive classification scheme for Alzheimer disease biomarkers. Neurology, 87, 539-547.

Johnson, W., Bouchard Jr, T. J., Krueger, R. F., McGue, M., \& Gottesman, I. I. (2004). Just one $\mathrm{g}$ : Consistent results from three test batteries. Intelligence, 32(1), 95-107.

Johnson, W., te Nijenhuis, J., \& Bouchard Jr, T. J. (2008). Still just 1 g: Consistent results from five test batteries. Intelligence, 36(1), 81-95.

Kendell, R. E. (1975). The concept of disease and its implications for psychiatry. The British Journal of Psychiatry, 127, 305-315.

Kotov, R., Krueger, R. F., Watson, D., Achenbach, T. M., Althoff, R. R., Bagby, R. M., ... \& Eaton, N. R. (2017). The Hierarchical Taxonomy of Psychopathology (HiTOP): A 
dimensional alternative to traditional nosologies. Journal of Abnormal Psychology, 126(4), 454-478.

Krueger, R. F., \& DeYoung, C. G. (2016). The RDoC initiative and the structure of psychopathology. Psychophysiology, 53, 351-354.

Krueger, R. F., Kotov, R., Watson, D. Forbes., M. K., Eaton, N. R., ... \& Zimmermann, J. (2018). Progress in achieving quantitative classification of psychopathology. World Psychiatry, 17, 282-293.

Latzman, R. D., DeYoung, C. G., \& The HiTOP Neurobiological Foundations Workgroup (2020). Using empirically-derived dimensional phenotypes to accelerate clinical neuroscience: The Hierarchical Taxonomy of Psychopathology (HiTOP) framework. Neuropsychopharmacology. Online publication before print, https://doi.org/10.1038/s41386-020-0639-6.

Leshner, A. I. (1997). Addiction is a brain disease, and it matters. Science, 278(5335), 45-47. Lewis, M. (2017). Addiction and the brain: Development, not disease. Neuroethics, 10, 7-18. Linscott, R. J., \& van Os, J. (2013). An updated and conservative systematic review and metaanalysis of epidemiological evidence on psychotic experiences in children and adults: On the pathway from proneness to persistence to dimensional expression across mental disorders. Psychological Medicine, 43, 1133-1149.

Markon, K. E., \& Krueger, R. F. (2005). Categorical and continuous models of liability to externalizing disorders: A direct comparison in NESARC. Archives of General Psychiatry, 62, 1352-1359.

Miller, G. A., Galanter, E., \& Pribram, K. H. (1960). Plans and the structure of behavior. New York: Holt. 
National Institute on Drug Abuse; National Institutes of Health; U.S. Department of Health and Human Services (2018). The National Institute on Drug Abuse media guide.

Powers, A. R., Kelley, M. S., \& Corlett, P. R. (2017). Varieties of voice-hearing: Psychics and the psychosis continuum. Schizophrenia Bulletin, 43 84-98.

Powers, W. T. (1973). Behaviour: The control of perception. Chicago, IL: Aldine.

Roberts, B. W., Luo, J., Briley, D. A., Chow, P. I., Su, R., \& Hill, P. L. (2017). A systematic review of personality trait change through intervention. Psychological Bulletin, 143(2), 117-141.

Scadding, J. G. (1967). Diagnosis: the clinician and the computer. The Lancet, 290, 877-882.

Seth, A. K. (2015). The cybernetic bayesian brain: From interoceptive inference to sensorimotor contingencies. In T. Metzinger \& J. M. Windt (Eds). Open MIND: 35(T). Frankfurt am Main: MIND Group.

Stein, D. J., Phillips, K. A., Bolton, D., Fulford, K. W. M., Sadler, J. Z., \& Kendler, K. S. (2010). What is a mental/psychiatric disorder? From DSM-IV to DSM-V. Psychological Medicine, 40, 1759-1765.

Wakefield, J. C. (1992a). The concept of mental disorder: On the boundary between biological facts and social values. American Psychologist, 47, 373-388.

Wakefield, J. C. (1992b). Disorder as harmful dysfunction: A conceptual critique of DSM-III-R's definition of mental disorder. Psychological Review, 99, 232-247.

Wakefield, J. C. (2007). The concept of mental disorder: Diagnostic implications of the harmful dysfunction analysis. World Psychiatry, 6(3), 149-156. 
Waller, R., Gardner, F., \& Hyde, L. W. (2013). What are the associations between parenting, callous-unemotional traits, and antisocial behavior in youth? A systematic review of evidence. Clinical Psychology Review, 33(4), 593-608.

Walton, K. E., Ormel, J., \& Krueger, R. F. (2011). The dimensional nature of externalizing behaviors in adolescence: Evidence from a direct comparison of categorical, dimensional, and hybrid models. Journal of Abnormal Child Psychology, 39, 553-561.

Widiger, T. A., \& Samuel, D. B. (2005). Diagnostic categories or dimensions? A question for the Diagnostic and Statistical Manual of Mental Disorders-Fifth Edition. Journal of Abnormal Psychology, 114(4), 494-504.

Widiger, T. A., \& Sankis, L. M. (2000). Adult psychopathology: Issues and controversies. Annual Review of Psychology, 51(1), 377-404.

Widiger, T. A., Sellbom, M., Chmielewski,, M., Clark, L. A., DeYoung, C. G. ... \& Wright, A. G. C. (2019). Personality in a hierarchical model of psychopathology. Clinical Psychological Science, 7, 77-92.

Widiger, T. A., Trull, T. J. (1991). Diagnosis and clinical assessment. Annual Review of Psychology, 42, 109-133.

Wiener, N. (1948). Cybernetics-or control and communication in the animal and the machine. New York, NY: MIT Press/Wiley.

Wouters, A. G. (2003). Four notions of biological function. Studies in History and Philosophy of Science Part C: Studies in History and Philosophy of Biological and Biomedical Sciences, 34, 633-668. 
Wright, A. G. C., Krueger, R. F., Hobbs, M. J., Markon, K. E., Eaton, N. R., \& Slade, T. (2013). The structure of psychopathology: Toward an expanded quantitative empirical model. Journal of Abnormal Psychology, 122, 281-294. 


\section{Footnotes}

1. "Cybernetic function" refers to the manner in which a mechanism facilitates the goal pursuit of the individual cybernetic system of which it is a part. "Evolutionary function" refers the manner in which the mechanism contributed to reproductive fitness such that it became speciestypical.

2. Borsboom et al. (2019) offer their own critique of the claim that mental disorders are brain disorders, which has both minor similarities and major differences from ours. The main point of similarity is their identification of the fact that psychopathology is often constituted and influenced by an individual's problematic desires, beliefs, and attitudes regarding their specific life circumstances (which we would label "characteristic adaptations"). Although these are neurally instantiated, they are not necessarily tied to any particular malfunction of the brain, which may simply have learned some habits that proved to be dysfunctional. Our major point of disagreement with their account is its reliance on the network theory of psychopathology (Borsboom, 2017), which assumes that all psychopathology is due to the causal interactions of specific symptoms and denies the existence of broadly acting common causes that might influence many symptoms and explain the existence of major dimensions of psychopathology, like Negative Affect or Disinhibition. These assumptions and the network theory approach in general are untenable, theoretically and empirically, for reasons we have detailed elsewhere (DeYoung \& Krueger, 2018b). 


\section{Figure Captions}

Figure 1. Causal processes in the functioning of personality and treatment of psychopathology. Solid arrows represent spontaneous causal processes. Dashed arrows represent therapeutic interventions. Both genetics and the environment directly influence the cybernetic mechanisms underlying personality traits (which are also dimensions of risk for psychopathology). Circular arrows indicate that cybernetic parameters can influence each other, as can characteristic adaptations and other life outcomes, such as physical health. Neurobiological interventions are aimed directly at changing the parameters of cybernetic mechanisms that cause variation in personality traits/dimensions of risk. Behavioral or talk therapy interventions are aimed directly at changing characteristic adaptations. Each kind of intervention can indirectly influence the target of the other. (Reprinted with permission from DeYoung \& Krueger, 2018a.) 
Figure 1

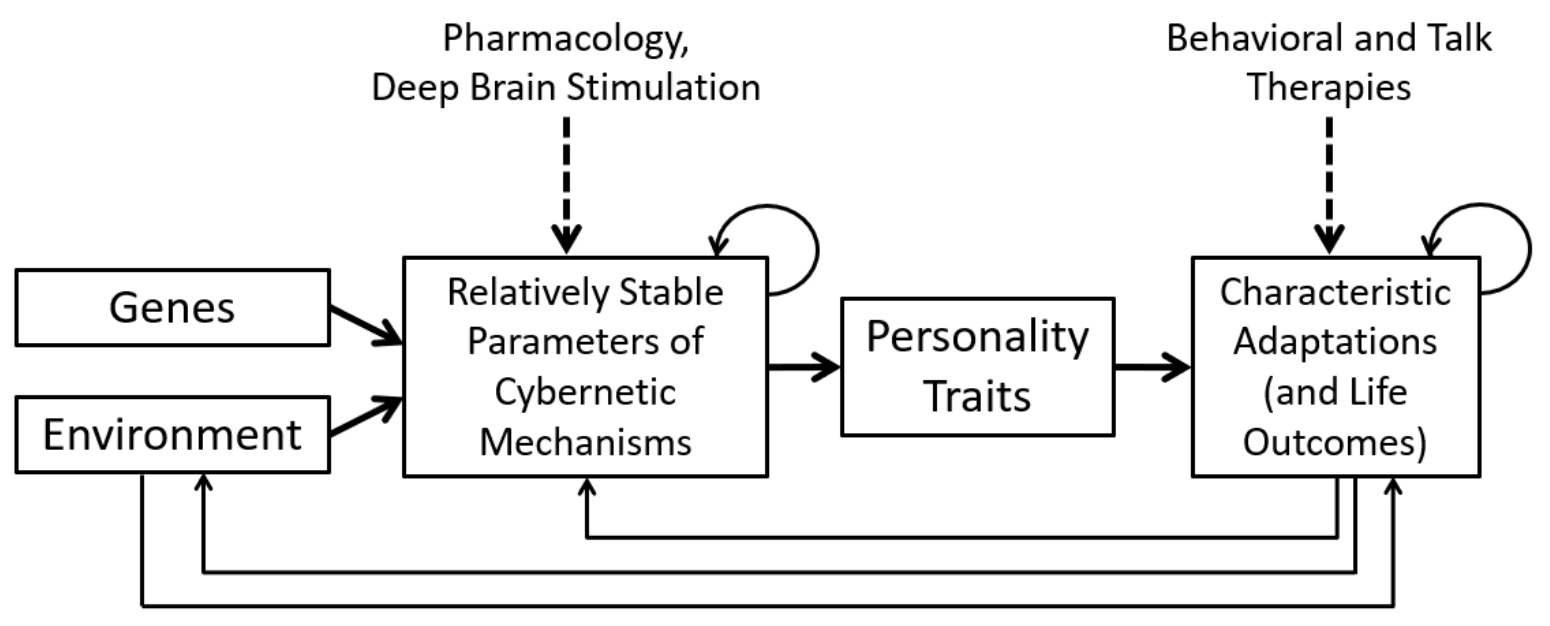




\section{Frequently Asked Questions about the Cybernetic Dysfunction Theory}

Supplement to "A cybernetic perspective on the nature of psychopathology: Transcending conceptions of mental illness as statistical deviance and brain disease." Journal of Psychopathology and Clinical Science.

\section{Colin G. DeYoung \& Robert F. Krueger}

1. Why do you distinguish between "mental disorder" and "psychopathology"? Aren't those really just two terms for the same thing?

2. Your use of the word "goal" is confusing. Isn't a goal a well-specified future state that people consciously value and make some degree of commitment to work toward through their actions?

3. Why are your definitions of psychopathology and mental disorder better than 's definition? (Including DSM-5, Wakefield, Boorse/Kendell, Bergner, Widiger, and Borsboom)

4. How does your theory deal with disorder X? (Including psychopathy, schizoid personality disorder, and addiction.)

5. Which goals need to be disrupted in order to identify disorder $X$ ?

6. Doesn't addiction have to be considered a brain disease because of the way drug use affects the brain over time?

7. You state that extremity on any major trait or dimension of psychopathology is insufficient to identify psychopathology. (a) Isn't that internally contradictory, given that you are talking about "dimensions of psychopathology." And (b) isn't the tendency to experience distress or negative emotion that is an aspect of Neuroticism or Negative Affect or Internalizing inherently indicative of psychopathology, if it is sufficiently extreme?

8. Doesn't your approach render everyone psychopathological? Is there anyone who can achieve all of their goals?

9. Many people have difficulty pursuing their goals because they are impoverished, imprisoned, or discriminated against. Should they be considered psychopathological?

10. Didn't cybernetics go out of style long ago? Doesn't it refer to primitive serial models of computation that rely only on negative feedback and set points and have little to do with the kinds of massively parallel processing that go on in brains?

11. If your approach is cybernetic, why doesn't it have a computational model associated with it? 
1. Why do you distinguish between "mental disorder" and "psychopathology"? Aren't those really just two terms for the same thing?

We find it useful to reserve one term, "mental disorder," to refer to official diagnostic entities that are used in medicine and another, "psychopathology," to refer to entities that meet scientifically justifiable criteria for a condition of mental illness (i.e., psychological disease/dysfunction) regardless of whether that condition warrants a diagnosis by official standards. The choice of these terms is somewhat arbitrary, but it is based primarily on the fact that "mental disorder" is the standard term used in medicine today for its official diagnostic entities - for example, in The Diagnostic and Statistical Manual of Mental Disorders, Fifth Edition (DSM-5; APA, 2013). (Note that this does not mean we endorse either the DSM5's definition of "mental disorder" or its diagnoses, as we discuss in Question 3; rather, we use the term mental disorders to refer primarily to the kind of official diagnoses that would replace the DSM-5 system if medicine were to embrace our theory.) There is nothing inherently or conventionally distinct about the meanings of "mental disorder" and "psychopathology" and much of the field uses them interchangeably. We do not, and we hope you'll humor us in order to understand what we're talking about. The distinction is important because our theory argues that psychopathology is a matter of objective fact, but we do not believe that deciding who should be diagnosed and treated will ever be purely a matter of objective fact. There will probably always be people with psychopathology mild enough that society deems them unsuitable for a diagnosis of "mental disorder," and that is not necessarily a flaw in the system.

\section{Your use of the word "goal" is confusing. Isn't a goal a well-specified future state that people} consciously value and make some degree of commitment to work toward through their actions?

That is probably the most common meaning of the word "goal" in psychology. However, we are using a broader definition of goal. In part, this is because cybernetics uses a much broader definition of "goal," in which the goal is simply any target state of a cybernetic system. A cybernetic system is one that has at least three separate components: (1) a controlled variable physically represented in the system, with a value or range of values toward which the system attempts to move (the goal); (2) a feedback process that allows comparison of the current state of the controlled variable with the goal state; (3) an operator or set of operators that are engaged when the current state does not match the goal and that have the effect of shifting the value of the controlled variable toward the goal.

On the cybernetic definition, the human organism contains many goals, not all of which are psychological (such as those involved in basic aspects of physiological homeostasis and control). Therefore, we limit the goals relevant to our theory to psychological goals, but even so we still use a broader definition of "goal" than psychologists typically do. We allow psychological goals to be unconscious and therefore not accessible for accurate self-report (note that we believe people can report reasonably accurately on many of their goals; we simply allow the possibility that some cannot be accurately reported because they are unconscious). We also allow them to be vague rather than well-specified, and we allow the existence of goals to which people have no current commitment to action. As long as the latter remain in memory, the function as desired states of the world that the person is not actively trying to bring about, which can nonetheless be consequential for the person's ongoing interpretation of experience. On our definition, many related psychological constructs are goals, including desires, motives, motivations, needs, and basic needs. Basic needs generally correspond to goals at very high levels of the goal hierarchy. 
Goals are arranged in a hierarchy in two ways. First, long-term or complex goals are typically accomplished through various subgoals, which in turn have their own subgoals, etc., down to the level of individual motor actions or cognitive operations. Goals that organize larger amounts of time, because they are higher up in this hierarchy of dependent goals, are more important than the lower-level subgoals they subsume and, therefore, more powerful in their capacity to induce emotional disturbance and psychopathology when they are disrupted. One complication to this assertion is due to the fact that certain goals can be subgoals for more than one higher-level goal, and so, if one of the higher-level goals is more important than the other, the shared subgoal could be more important than the less important of the two higher-level goals. We have illustrated human goal hierarchies schematically with the following figure (reprinted with permission from DeYoung \& Krueger, 2018a.):

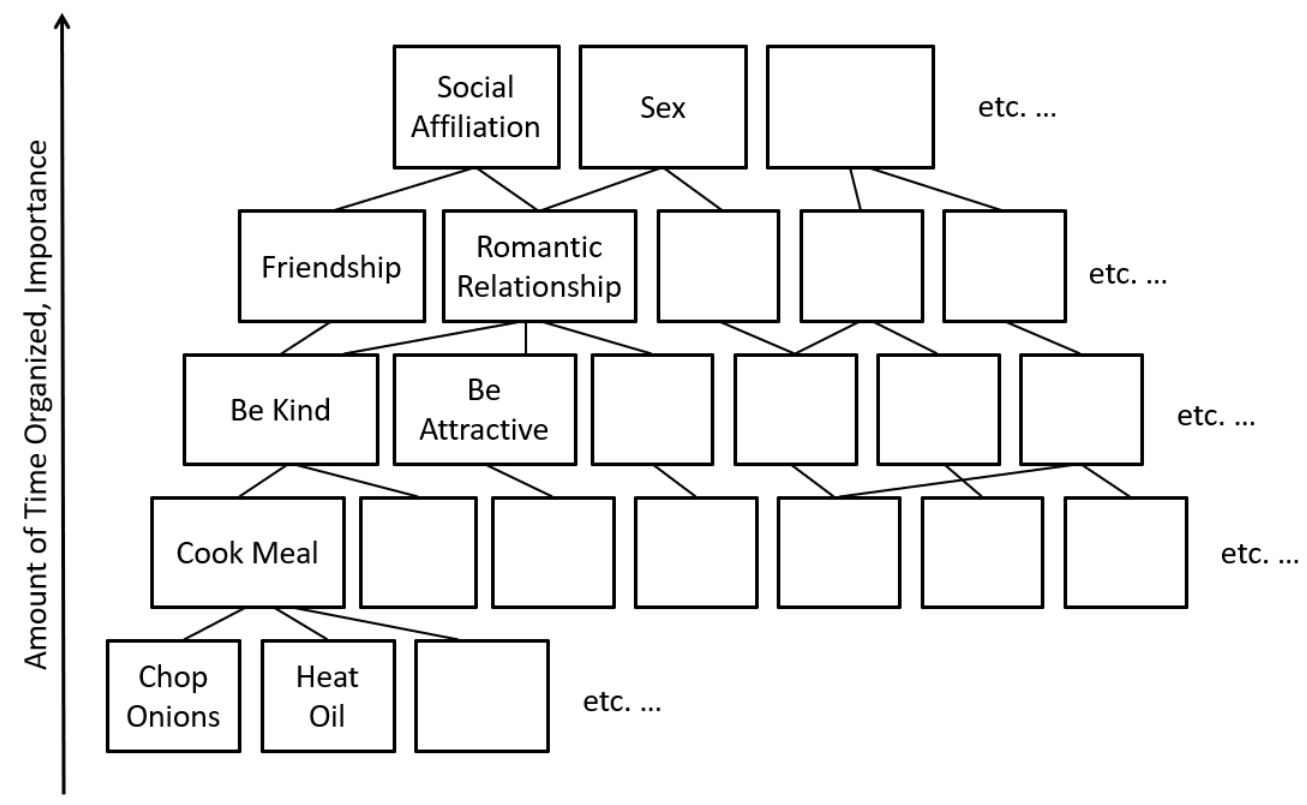

This shows a hierarchical structure of goals for a hypothetical individual. Lines between levels indicate dependence of goals on subgoals and indicate (a) that goals often require multiple subgoals and (b) that goals sometimes advance multiple superordinate (higher-level) goals.

The second way in which goals are organized hierarchically has to do with their relative importance at a similar level of abstraction or generality (within a single row in the figure, for example). Even at the same or similar levels of the depicted hierarchy, different goals will often be assigned different priorities. This aspect of priority in the goal hierarchy is not shown in the figure, but again the relative importance of goals that are disrupted is what determines the severity of psychopathology. Psychopathology increases with the number and importance of the goals that are disrupted.

Our theory asserts that there is a fact of the matter about the contents and organization of people's goal hierarchies, at any given time, even though that structure may not be entirely clear to the person or to the clinician evaluating them. The best that can be done in assessing psychopathology is to try to identify the person's important goals as accurately as possible based on information available from self-reports, interviews, or other sources. For additional treatment of the nature of goals in our theory see DeYoung, 2015; DeYoung \& Krueger, 2018a, 2018b; DeYoung \& Weisberg, 2019. 
Our definition is that psychopathology is persistent failure to move toward one's goals, due to failure to generate effective new goals, interpretations, or strategies when existing ones prove unsuccessful. Our definition of mental disorder is psychopathology severe enough to be deemed consistently appropriate for treatment by the medical establishment. We will review a few prominent or otherwise interesting alternative definitions. These do not distinguish between "mental disorder" and "psychopathology," but we will generally discuss which of these they resemble in our definitions.

DSM-5. "A mental disorder is a syndrome characterized by clinically significant disturbance in an individual's cognition, emotion regulation, or behavior that reflects a dysfunction in the psychological, biological, or developmental processes underlying mental functioning. Mental disorders are usually associated with significant distress or disability in social, occupational, or other important activities. An expectable or culturally approved response to a common stressor or loss, such as the death of a loved one, is not a mental disorder. Socially deviant behavior (e.g., political, religious, or sexual) and conflicts that are primarily between the individual and society are not mental disorders unless the deviance or conflict results from a dysfunction in the individual, as described above" (APA, 2013, p. 20).

The DSM-5's definition is obviously proposed in the context of deciding when diagnosis should occur and hence corresponds more closely to our definition of mental disorder rather than psychopathology. This is perhaps most evident in its use of the phrase "clinically significant," which is never clearly defined but allows for the extra-scientific decisions that we take to be the hallmark of identifying mental disorder as opposed to just psychopathology. In other words, on the DSM-5 definition, it is possible to have a "dysfunction" that is deemed not to be clinically significant and therefore is not a mental disorder. Thus, "dysfunction" in the DSM-5 definition might correspond to our definition of "psychopathology"; however, it is impossible to tell because DSM-5 never defines "dysfunction." This is problematic because, as we have noted, there are several distinct viable definitions of "dysfunction" (DeYoung \& Krueger, 2018a; Wouters, 2003). Nor does the DSM-5 define "disability" or "impairment," two other constructs that seem at least superficially relevant to our definition of psychopathology. Note also that, because the DSM-5 definition says merely that mental disorders are "usually" associated with disability, disability is, therefore, not technically part of the general definition of mental disorder because one can have mental disorder in some cases without disability. In short, the DSM-5 definition is so vague about many of its key terms that it is obviously a poor definition from a scientific or philosophical perspective.

Another important point of comparison is in relation to the exceptions specified in the DSM definition for responses to common stressors or losses and for socially deviant behavior. On our theory, stress or loss can cause psychopathology when it disrupts people's goal pursuit and they are unable to adapt afterward in order to resume goal pursuit. One way to adapt would be for the person to accept that they may be unable or uninterested in pursuing their important goals temporarily, while they recuperate or grieve. This involves a temporary deprioritization of certain goals in favor of other goals, thereby changing the person's goal hierarchy. After the person has recovered to a sufficient degree, they may shift their priorities back to focusing on their other goals, thereby increasing their importance again. Typically, stress or loss causes psychopathology when people's reactions to the precipitating event go on longer than 
they expect and they are not able to reprioritize their goals effectively or to develop other strategies for coping effectively with their reactions.

Socially deviant behavior does not constitute psychopathology, according to our theory, but it can cause psychopathology if it prevents the person from pursuing their important goals (some of which may themselves be socially deviant). If it does prevent them, nonetheless it is not the fact that the behavior is socially deviant, per se, that makes the person psychopathological. Society may punish the person for socially deviant behavior or thwart that behavior, and this can cause psychopathology if the person is not able to change their goals or to find a way to work around society's interference. It is easy, and probably appropriate, to blame society in cases where behavior that does not harm others is stigmatized or criminalized (as has sometimes occurred historically with homosexuality, for example; note that this is not to say that homosexuality is psychopathology, but rather that society may cause psychopathology in homosexual people, often resulting in depressive or anxious features). In cases where others are likely to be harmed, however, societal interference may be appropriate, which means that it is sometimes acceptable for society to risk causing psychopathology in order to prevent harm to others. One would hope, in such cases, that society would also be willing to offer mental health care when necessary.

In sum, we do not see a need to include any exceptions to our definition of psychopathology, which we take to be a strength of the definition in and of itself.

Wakefield (1992, 2007). Mental disorder is "harmful dysfunction." "A condition is a disorder if it is negatively valued ('harmful') and it is in fact due to a failure of some internal mechanism to perform a function for which it was biologically designed (i.e., naturally selected)." Wakefield (2007, p. 149) further defines "harmful" as "judged negative by sociocultural standards," which is an unusual definition of "harm." On Wakefield's account, "dysfunction" is closer to our notion of psychopathology, whereas the addition of the socially adjudicated "harm" criterion renders the whole definition closer to our notion of mental disorder. We discussed the problems with this theory extensively in a previous publication (DeYoung \& Krueger, 2018a). In short, the main problem is that Wakefield relies on an evolutionary definition of "dysfunction," whereas we rely on a cybernetic definition of "dysfunction" that we believe provides a definition of psychopathology that is more coherent, more scientifically tractable, and more in line with medical, academic, and lay understandings of psychopathology.

Boorse (1977, 2014). "A pathological condition is a state of statistically species-subnormal biological part-function, relative to sex and age" (Boorse, 2014, p. 684). We critique Boorse's definition in the article to which this is a supplement. In a previous article, we discussed some additional concerns about his definition of "function" as referring to the manner in which the part in question facilitates current survival and reproduction (DeYoung \& Krueger, 2018a). Boorse's definition is nearly identical to that of the psychiatrist Kendell (1975), who used the term "biological disadvantage" to refer to reductions in survival and fertility, but Boorse's definition is more thoroughly elaborated. Although Boorse claims to have developed an objective definition of disease that would be parallel to our notion of psychopathology, in fact he acknowledges that the decision about how far from the norm function must be to indicate pathology is "arbitrary" or "conventional," such that, in reality, the full definition is closer to our notion of mental disorder. 
Bergner (1997). Psychopathology is "significant restriction in the ability of an individual to engage in deliberate action and, equivalently, to participate in available social practices" (Bergner, 1997, p. 246). (We thank an anonymous reviewer for pointing us toward this definition and the next one.) This definition has superficial similarities to our definition of psychopathology, especially in its first half. "Deliberate action" suggests voluntary, goal-directed action, and our definition involves failure in that domain. However, Bergner (1997, p. 238) defines a disability in deliberate action as "being unable in some significant measure (a) to know what one is doing and/or (b) to control (initiate or restrain) one's behavior." These are indeed likely causes of psychopathology, from our perspective, as they may prevent people from pursuing their goals effectively, but they are not necessary and sufficient for psychopathology. In the article to which this is the supplement, we discuss the example of healthy psychics whose regular auditory hallucinations lead them to believe that they are communicating with spirits from other realms (Power et al., 2017). In an important sense, these people do not know what they are doing (as they appear to be mistaken about the nature of the world and their actions), but they are nonetheless not psychopathological. Regarding part (b), we do not think the mere fact that people are able to control their own behavior is any guarantee that they will avoid psychopathology. A person with normal levels of behavioral control (similar to Conscientiousness and Stability, in trait terms; DeYoung \& Rueter, 2016) may nonetheless find themselves unable to figure out how to act in such a way as to pursue their important goals effectively. It is easy to imagine someone who is severely depressed, not in the manner of feeling unable to motivate themselves to initiate any behavior, but rather in the manner of not having any clear sense of what to do and hence feeling completely hopeless. On the whole, therefore, Bergner's view of deliberate action does not provide a viable alternative to our view of cybernetic function.

Additionally, we do not think that inability to participate whole-heartedly in social practices that are demographically normative (as Bergner describes the second half of his definition) is necessarily indicative of psychopathology unless the person wants to participate in social practices or needs to participate in social practices in order to pursue some of their important goals. Obviously, most people want to participate in social practices, so for most people this ability is crucial for their mental health. However, we do not find it necessary to make this definitional for psychopathology, and we acknowledge the rare exception, like the "schizoid" hermit mentioned in our response to Question 4. Our theory avoids these problems by specifying persistent failure of goal pursuit (for whatever reason), rather than social participation, to be the criterion for psychopathology.

Widiger \& Sankis (2000); Widiger \& Trull (1991). Mental disorders are "dyscontrolled [or "involuntary"] organismic impairments in psychological functioning" or "dyscontrolled maladaptivity" (Widiger \& Sankis, 2000, p. 383). "Persons who are hindered in their ability to adapt flexibly to stress, to make optimal life decisions, to fulfill desired potentials, or to sustain meaningful or satisfying relationships as a result of an impairment in cognitive, affective, and/or behavioral functioning over which they have insufficient control, have a mental disorder." (Widiger \& Trull, 1991, p. 112). Widiger and colleagues draw approvingly on Bergner's (1997) claims about deliberate action, but they make a broader claim about the range of abilities that are involved in psychopathology. These include "fulfill[ing] desired potentials," which sounds a lot like pursuing important goals successfully. Still, there is a lot of vagueness: "Optimal" life decisions by what criterion? What does adapting "flexibly" entail? What constitutes an "impairment"? What determines whether control is "insufficient" given that voluntary control over human function is never complete? What does it mean for an impairment to be 
"organismic" - what other kinds of impairment are there? Although "maladaptivity" is not explicitly defined, it seems closer to our cybernetic usage of "adaptive," referring to that which allows effective goal pursuit, rather than to the evolutionary sense of "adaptive." If "maladaptivity" is inability to pursue goals (including basic needs) effectively, and "dyscontrolled" indicates that the person is not able voluntarily to develop new goals or strategies or interpretations (including emotional reactions) in order to resume effective goal pursuit, then this definition is very close in spirit to ours. However, we think it would become more coherent if it acknowledged explicitly that persistent disruption of the pursuit of important personal goals forms the core of its criteria for psychopathology. Widiger and Sankis (2000, p. 383) wrote, "People seek professional intervention in large part to obtain the insights, techniques, skills, or other tools (e.g. medications) that increase their ability to better control their mood, thoughts, or behavior"- to which we would add, in order to pursue their important goals effectively, because that is inherently implied by the word "control" from our cybernetic perspective. Any cybernetic control system has at least one goal.

Borsboom (2017). Network theory defines mental disorder as "the (alternative) stable state of a strongly connected network," where the nodes in the network are "the problems that have been codified as symptoms in the past century and appear as such in current diagnostic manuals," and the edges (connections) of the network are "direct causal connections between symptoms" (Borsboom, 2017, pp. 7 \& 9). In contrast, when symptoms are weakly causally connected, the network can be in a stable state of good mental health. One weakness of Borsboom's definition is that it offers no scientific or rational criterion for what is considered a symptom, instead relying only on accumulated medical wisdom. Additionally, it offers no explanation of what it is about the stable state of a strongly connected network of symptoms that makes it definitionally pathological, beyond referring vaguely to the kinds of "problems in living" with which people present to mental health professionals. The idea that mental disorder is what people complain about to mental health professionals plus what those professionals officially agree are symptoms does not provide much of a foundation to build on scientifically or philosophically. (Some have argued that this sort of definition is "almost worse than no definition at all"; Kendell, 1975.)

Further, it seems likely that one could identify a set of "symptoms" that were strongly interrelated in the individual over extended periods of time (anxious arousal, difficulty concentrating, and rumination, for example), such that they generally tended to co-occur, but where the person did not feel sufficiently debilitated by these problems, even when under stress, to go seek professional health care. For that matter, this same person might well not show any obvious psychopathology under our definition or under any of the other definitions we discuss here. In fact, one likely problem for the network theory is that many clusters of symptoms are likely to be highly correlated within people whether or not they are suffering from psychopathology according to other definitions, simply because the symptoms in the cluster share some underlying mechanism, and thus they will tend to co-occur consistently, even if they occur only rarely. For example, the neural mechanisms of anxiety have been studied extensively and can explain the co-occurrence of anxious arousal, difficulty concentrating, and rumination (Gray \& McNaughton, 2000). This highlights a serious problem with the network theory that we have discussed before, namely that it insists that such correlations among symptoms must be due to direct causal connections and denies the existence of any broad common causes that influence multiple symptoms (DeYoung \& Krueger, 2018b). The effects of such broad common causes, assuming the causes themselves are unmeasured, can be appropriately accounted for, in a network model, by latent variables. (Indeed, many latent-variable and network models are fungible, further undermining the claim that "direct causal connections" exhaust the 
universe of explanations for observed correlations among symptoms; Bringman \& Eronen, 2018.) If a network model of the type endorsed by Borsboom includes a group of nodes that share an unmeasured cause and does not include a corresponding latent variable, it will be distorted and hence inaccurate. Unfortunately for the network theory, in many cases mechanisms that function as common causes for multiple symptoms are known or hypothesized based on preliminary evidence, even if the manner of their functioning that causes psychopathology is not entirely understood (DeYoung \& Krueger, 2018a, 2018b). Our theory explicitly acknowledges the existence both of causal interactions between relatively specific symptoms and of more broadly acting forces that cause groups of symptoms to covary.

\section{How does your theory deal with disorder X?}

This is a common way to test theories of psychopathology conceptually: start with something that the questioner thinks everyone agrees is an example of psychopathology and see whether the theory comes to the same conclusion. One issue here is that the disorders invoked are often categorical diagnoses from $D S M-5$, and we stress that our theory follows the evidence that these diagnoses are scientifically invalid. It does not appear that any common mental disorder identified by the DSM-5 is in reality a discrete, categorical entity (Carragher et al., 2014; Haslam et al., 2020; Markon \& Krueger, 2005; Walton et al., 2011; Widiger \& Samuel, 2005; Wright et al., 2013). The traditional diagnoses, like schizophrenia, major depressive disorder, borderline personality disorder, etc., are heterogeneous collections of symptoms that do not reflect the way symptoms co-occur in reality, with arbitrary cutoffs for exactly how severe various symptoms must be to infer presence of disorder (Kotov et al., 2017). There is no need for a scientific theory of psychopathology to explain diagnoses that are themselves invalid and describe nonexistent categories. With that being said, we want to be very clear that we are not denying the reality of mental illness or the reality of the problems of people who receive these diagnoses. For the purposes of answering the question, "How does your theory deal with disorder X?" we are willing to consider the various symptoms that are subsumed by that disorder (e.g., delusions, hopelessness, dysregulated affect).

Psychopathy. The problem we get asked about most frequently is not an official DSM-5 diagnosis in Section II (diagnostic criteria and codes), but it is widely studied and also recognized as a diagnostic concept in the Alternative DSM-5 Model of Personality Disorders (AMPD), as a specifier for antisocial personality disorder. Because our criterion for psychopathology refers exclusively to the inability of people to pursue their own goals, people worry that we will not be able to identify, as psychopathological, disorders in which people exploit or hurt other people while pursuing their own goals effectively. To some extent, their concerns are warranted. We do not think that causing other people to suffer (interfering with others' goals or physical well-being) is itself a good criterion for mental illness. However, it is frequently a cause of mental illness because pursuing one's own goals very often requires getting along with others. People with the extremely callous and antisocial traits labeled as "psychopathy" often end up in jail repeatedly, despite the fact that they presumably value their freedom (i.e., have a goal of not being jailed), so it is clear that their callous, antisocial behavior often causes psychopathology, on our theory. However, the rare psychopaths who somehow manage to exploit or hurt others while still effectively pursuing all of their other goals are not mentally ill on our account - but they are likely to be criminal. They must be stopped or controlled by their acquaintances or by the justice system, not by the mental health system. This does not mean that mental health care should not be given to people considered "successful psychopaths," if there is evidence that such treatment will reduce the risk that they hurt others and sabotage themselves. High levels of callousness and antisocial behavior are inherently a risk for 
psychopathology, even though they are not direct criteria for psychopathology in our theory, because they increase the likelihood that the person will not be able to pursue their goals effectively. We believe that interventions for individuals at high risk for psychopathology can contribute to the greater good of society as well as the good of the individuals themselves (e.g., prevention efforts directed at children with a tendency to be unusually callous; Waller et al., 2013).

Schizoid Personality Disorder. We interpret the problems that get labeled as "schizoid" in terms of extreme levels of detachment, a construct from empirically derived, dimensional models of psychopathology (e.g., Kotov et al., 2017). These problems might seem to pose a challenge to our theory if they entail that the person simply has no goals for close relationships. However, our theory would not consider a severely detached person to have psychopathology unless they were unable to pursue their own goals effectively. In this regard, our theory is not so different from the diagnostic criteria in DSM, in which schizoid traits would not be considered to indicate a personality disorder unless they led to "clinically significant distress or impairment in social, occupational, or other important areas of functioning." The main difference is that, using our model, the assessment would need to consider whether the person truly had an absence of any desire for relationships or whether they had some such desire (potentially that they were not fully or clearly aware of) that they were unable to fulfill because of their extreme detachment. (In the article for which this is the supplement, we wrote, "people who believe they have little need for social affiliation may be mistaken.") However, if the person truly had no desire for relatedness and was content with a lack of relationships, they would not have psychopathology from our perspective, unless their detachment were interfering with other goals that they did have (which often happens, of course, given that many goals depend on social relationships of one kind or another for their fulfillment). The "schizoid" hermit who is content living alone in the woods off the grid and never desires to interact with people is not psychopathological according to our theory.

The example of "schizoid" traits is sometimes brought up as a prelude to what is hypothetically an even more severe case, in which someone claims to have no goals at all (not just an absence of goals in one particular domain of functioning like close relationships). How does our theory handle the case in which the person has no goals, if psychopathology requires failing to pursue goals effectively? In short, we do not think such a case can exist. People are cybernetic systems and cybernetic systems are fundamentally goal directed. Even a severely depressed person who says they value nothing at all and has insufficient motivation to get out of bed is typically not pleased to be depressed and would rather be able to get out of bed. Those constitute goals on our definition. It is difficult to extinguish people's very basic goals to feel pleasure and avoid displeasure, even when their pursuit is rendered extremely difficult by depression. Even if certain unusual people consciously truly believe they have no goals, we strongly suspect that they are mistaken and that, unconsciously, psychological goals persist.

Addiction. In a previous article, we answered the question of how our theory would deal with an alcoholic whose goal was to stay drunk and who was successful in doing so (DeYoung \& Krueger, 2018b). Would this person not have psychopathology because of their success in pursuing this goal? The answer is clearly no because this person's drinking would probably be interfering with other important goals they are likely to have, such as staying healthy and maintaining good relationships. In order to determine the presence or absence of psychopathology, from our perspective, one must consider all of the person's goals at once. In Question 6 we discuss why we don't think addiction should be considered a "brain disease." 


\section{Which goals need to be disrupted in order to identify disorder X?}

This question is a variant of the previous question but reveals a serious misunderstanding of our theory. First, as noted, our theory generally does not endorse the existence of "disorder X" when that refers to a traditional categorical diagnosis. Second, our theory identifies the presence of psychopathology only in terms of the person's inability to pursue their own important goals effectively, regardless of what goals those are.

Identifying psychopathology therefore entails getting an understanding of people's characteristic adaptations: their goals, the strategies they use to pursue their goals, and the ways they interpret themselves and the world. As a second step in clinical evaluation, we recommend characterizing people in terms of common features of psychopathology using a dimensional model, like the one illustrated below (adapted from DeYoung \& Krueger, 2018a; see also DeYoung et al., 2016; Allen et al., 2019) or the more detailed model supplied by the Hierarchical Taxonomy of Psychopathology (Kotov et al., 2017), but this step has nothing to do with determining whether psychopathology is present. If psychopathology is present, one might think of this second step as asking whether the person is manifesting any of the common features of psychopathology, most of which happen to correspond to personality trait dimensions.

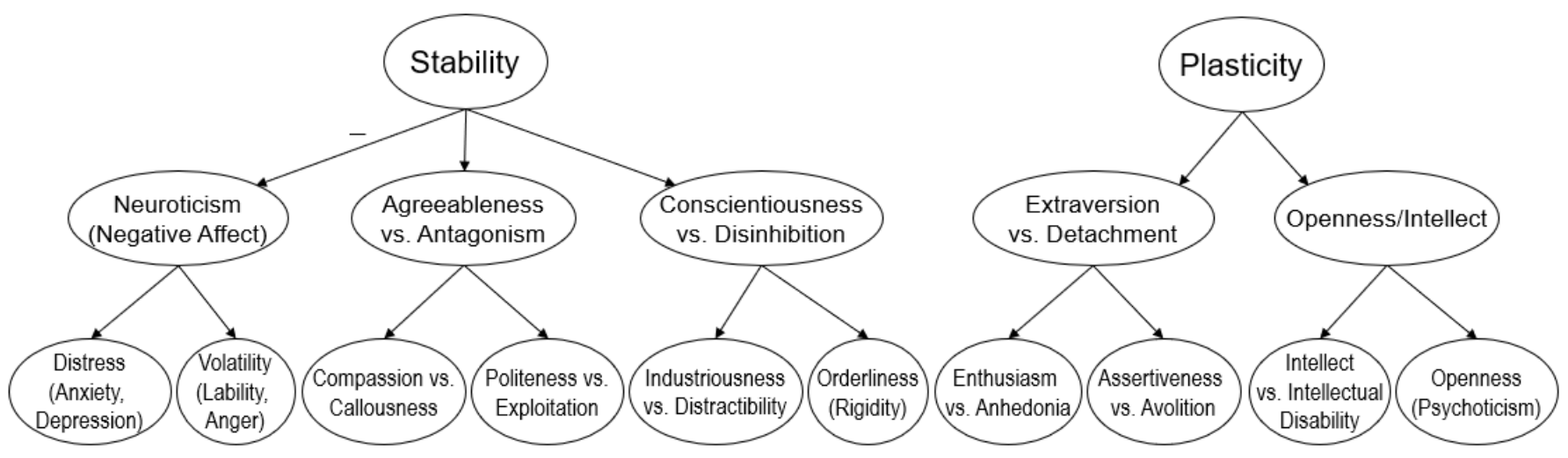

In our theory, there are broad (high-level) goals associated with these dimensions (e.g., remaining focused as a goal associated with Consciousness, or acquiring new information as a goal associated with Openness/Intellect), but there are also many goals that are defined in relation to the person's specific cultural or unique circumstances, which are characteristic adaptations rather than traits (DeYoung, 2015). All of the person's goals, whether traits or characteristic adaptations, are relevant to identifying the presence of psychopathology, but the broad goals associated with traits will always have to be accomplished through subgoals that are characteristic adaptations - where the rubber meets the road, so to speak. Hence characteristic adaptations are always disrupted in psychopathology. The presence of extremity on any particular trait dimension does not inherently indicate psychopathology because the person may be able to compensate for their extreme trait through their characteristic adaptations. For example, someone who is very high in Detachment may find a job that requires minimal interaction with people and a romantic partner who does not require a lot of expressive affiliation. 
Nonetheless, having extreme trait levels does tend to carry a risk for psychopathology and is often a contributing cause, helping to explain why the person has not been able to pursue their goals effectively. Returning to the question we began with, the nature of the goals disrupted in psychopathology does not necessarily indicate the causes of the person's psychopathology. In Question 4, for example, we mentioned that someone might have a problem with addiction, even though they were successful in pursuing their goal of remaining consistently intoxicated, because goals in unrelated domains were disrupted.

\section{Doesn't addiction have to be considered a brain disease because of the way drug use affects the brain over time?}

In the article to which this is a supplement, we critique the popular idea that psychopathology is "brain disease." Someone might be sympathetic to our argument in general but still believe that addiction is an exception and could reasonably be considered brain disease. However, we do not think that addiction should be considered a "chronic, relapsing brain disease" (NIDA, 2018), despite the fact that it involves the brain and that, like many other psychopathologies, it involves risk for relapse following recovery. On our theory, someone who previously suffered from drug addiction but no longer uses drugs in a manner that undermines the pursuit of their important goals (even if they occasionally still use the drug to which they were addicted) no longer has psychopathology. Addiction is a chronic disease only to the extent that a person has chronic cybernetic dysfunction. The brains of addicts change in ways that reflect both habituation to the drugs to which they are addicted and the potently rewarding properties of those drugs, but they also often change back to more normal configurations once addiction has ended (Lewis, 2017). Many of the changes in the brain that accompany addiction (whether the addiction is to a drug or to a behavior like gambling) are not in themselves pathological. It is only when the habit that they govern interferes with the person's other important goals in life that psychopathology is present. As with other forms of psychopathology, some direct biological interventions may be effective for treating addiction, but behavioral interventions can also be effective (and many addicts recover without treatment; Heyman, 2013). It has been argued that the fact " $[\mathrm{t}]$ hat addiction is tied to changes in brain structure and function is what makes it, fundamentally, a brain disease" (Leshner 1997, p. 46)." In reality, however, these changes do not differentiate addiction from any other form of learning- and experience-dependent changes in brain function. It is true that psychotropic drug exposure is unusual in that it acts directly on the brain, but nonetheless many of the changes that it causes are not qualitatively distinct from those caused by other impactful experiences (which is why it makes sense to consider behavioral addictions true addictions). There may be other brain changes that are specific to the drug in question, so the drug may have a pathogenic effect on the brain, but that is not what makes drug addiction a psychopathology, so it does not make psychopathology associated with drug addiction a brain disease. Rather this sort of effect of a specific drug on the brain would suggest that there are neurological problems that may accompany some forms of drug use.

7. You state that extremity on any major trait or dimension of psychopathology is insufficient to identify psychopathology. (a) Isn't that internally contradictory, given that you're talking about "dimensions of psychopathology." And (b) isn't the tendency to experience distress or negative emotion that is an aspect of Neuroticism or Negative Affect or Internalizing inherently indicative of psychopathology, if it is sufficiently extreme? 
(a) The phrase "dimensions of psychopathology" is admittedly somewhat misleading, given that we specify that extremity on those dimensions does not inherently constitute psychopathology. Really, the dimensions in question represent variation in psychological features that carry risk for psychopathology and that often accompany psychopathology. But "dimensions of psychopathology" is a common way to describe them in the field of quantitative psychopathology, and we sometimes use it as shorthand.

(b) It is true that many people who have very high levels of Negative Affect will have some degree of psychopathology because one of most people's important goals is not to experience too much negative emotion. The more extreme one gets on any dimension of risk for psychopathology, the more likely it is that one will have psychopathology, and that is probably especially true for Negative Affect. We discussed this in a previous article (DeYoung \& Krueger, 2018a). The reason this does not contradict our theory is that the rare person who has gotten over their desire not to experience negative affect will not have psychopathology, on our definition, even if they experience a lot of negative affect. In the extreme, such as with panic attacks, this might be hard to imagine, but one can probably more easily imagine highly neurotic people who have gotten so used to experiencing a lot of anxiety that they simply develop strategies to compensate and to keep their anxiety to a manageable level, while accepting that they are simply going to experience fairly intense anxiety frequently. We would argue that if these people are able to pursue their important goals and generally accept their anxiety levels, they are not mentally ill. At any rate, it is not the presence of distress that indicates psychopathology, in our definition, but the inability to pursue goals; it happens that avoiding high levels of distress is an important goal for most people, so our definition does not contradict most people's sense that distress is typically central to psychopathology.

\section{Doesn't your theory render everyone psychopathological? Is there anyone who can achieve all of their goals?}

Many or even most people will experience psychopathology at some point during their lives. This is already true using the existing official criteria for mental disorder. We expect that virtually all people will suffer from physical illness at some point during their lives, so why should we not expect that most people will suffer from psychopathology too? At the same time, our theory certainly does not render everyone psychopathological all the time; not even close. Undoubtedly, few if any people will ever be able to achieve all of their goals in life, and most will not even be able to achieve all of their important goals, but this is not enough to indicate psychopathology. This is why the second half of our definition is so important. If pursuit of an important goal is disrupted, that does not by itself constitute psychopathology. Only if one is unable to adapt, following the disruption, by changing goals or strategies or interpretations such that one again becomes able to make progress toward one's important goals, does psychopathology appear. Further, it is often not the final achievement of a goal that is at issue in psychopathology (at least for longer-term goals) but rather successful versus unsuccessful movement toward the goal in question, which entails achieving subgoals.

We do not know whether more or fewer people would be considered psychopathological under our definition than under other definitions. On the one hand, because we acknowledge the existence of psychopathology that might not reach whatever severity would be granted a diagnosis of mental disorder, our system might allow some people to be recognized as having problems that could benefit from treatment even if they would not previously have been eligible for a diagnosis. On the other hand, some people might be considered merely unusual (but capable of pursuing their important goals) under our 
definition, where previously they might have been diagnosed. We do think that our definition would help to reduce the degree to which mental illness is something that adheres to one's identity forever, as so often happens with diagnoses in the current system. As soon as one regains the ability to pursue one's important goals, one ceases to have psychopathology from our perspective. This feature of our definition should help to destigmatize mental illness. Psychopathology reflects a state that one can be in, rather than anything inherent in one's traits or characteristics or features, no matter how unusual or challenging those may be.

\section{Many people have difficulty pursuing their goals because they are impoverished, imprisoned, or} discriminated against. Should they be considered psychopathological?

It is well known that poverty, incarceration, and discrimination are risk factors for psychopathology. Our theory is fully consistent with that. External as well as internal factors can trigger psychopathology, in our theory, just as in more traditional approaches. Importantly, our theory requires not only that people's goal pursuit is interrupted but also that they then fail to adapt to the interruption. Many people who are impoverished, imprisoned, or discriminated against are able to adapt in various ways so that they can continue to pursue their important goals. This adaptation may entail changing their goals or at least adjusting their expectations about the level at which those goals are going to be met. It may also involve changing strategies for pursuing existing goals. As an extreme example, someone imprisoned will need to radically change their goals and strategies at least temporarily, but if they can do so, they may remain mentally healthy until they are released and can then re-prioritize some of the goals that they had previously (while perhaps abandoning or adjusting any goals that may have contributed to their imprisonment in the first place).

10. Didn't cybernetics go out of style long ago? Doesn't it refer to primitive serial models of computation that rely only on negative feedback and set points and have little to do with the kinds of massively parallel processing that go on in brains?

Following Gray (2004) and Seth (2015), we are using the term cybernetics synonymously with control theory to refer to the field that developed out of the original cybernetic approaches (Ashby, 1956; Miller et al., 1960; Powers, 1973; Wiener, 1948), which studies the principles governing goal-directed systems that self-regulate via feedback. As applied to human information processing, the modern version of cybernetics recognizes that much processing takes place in parallel and that brains employ positive feedback and feedforward, as well as negative feedback, in their control processes (DeYoung \& Krueger, 2018b). Further, modern cybernetic approaches do not consider "set points" to be the only form of goal. Set points are single values of a controlled variable that do not change (or change only infrequently in response to dramatic events). In complex cybernetic systems, goals may shift dynamically and continuously based on the internal state and external environment of the system, and they may interact with each other through mechanisms of suppression and facilitation. Further, goals need not be single values but can be target ranges of values of a controlled variable. They could even be an open-ended range, such that more is always better or that any value is tolerated by the system if it is not above or below a certain value. 
11. If your theory is cybernetic, why doesn't it have a computational model associated with it?

We have written about this before (DeYoung \& Krueger, 2018b). The short answer is that computational models are not likely to provide insight into human functioning if they are not highly faithful to the system that they are modeling. Our theory is about the entire operation of the human being, and we are nowhere near a sufficient understanding of the brain to create a model of a human being that would be able to test our theory usefully. Instead, our theory provides more specific testable hypotheses about the mechanisms associated with dimensions of risk for psychopathology and the ways in which they might be associated with success and failure of people's characteristic adaptations (DeYoung \& Krueger, 2018a). We rely on the principles of cybernetics but not the mathematical formalisms (so far). 


\section{Supplemental References}

Allen, T. A., DeYoung, C. G., Bagby, M. B., Pollock, B. G., \& Quilty, L. C. (2020). A hierarchical integration of normal and abnormal personality dimensions: Structure and predictive validity in a heterogeneous sample of psychiatric outpatients. Assessment, 27, 643-656.

American Psychiatric Association (2013). Diagnostic and statistical manual of mental disorders, fifth edition. Arlington, VA: American Psychiatric Association.

Ashby, W. R. (1956). An introduction to cybernetics. London, UK: Chapman and Hall.

Bergner, R. M. (1997). What is psychopathology? And so what? Clinical Psychology: Science and Practice, 4(3), 235-248.

Boorse, C. (1977). Health as a theoretical concept. Philosophy of science, 44(4), 542-573.

Boorse, C. (2014). A second rebuttal on health. Journal of Medicine and Philosophy, 39, 683-724.

Borsboom, D. (2017). A network theory of mental disorders. World Psychiatry, 16, 5-13.

Bringmann, L. F., \& Eronen, M. I. (2018). Don't blame the model: Reconsidering the network approach to psychopathology. Psychological Review, 125(4), 606-615.

Carragher, N., Krueger, R. F., Eaton, N. R., Markon, K. E., Keyes, K. M., Blanco, C., . . Hasin, D. S. (2014). ADHD and the externalizing spectrum: Direct comparison of categorical, continuous, and hybrid models of liability in a nationally representative sample. Social Psychiatry and Psychiatric Epidemiology, 49, 1307-1317.

DeYoung, C. G. (2015). Cybernetic Big Five Theory. Journal of Research in Personality, 56, 33-58.

DeYoung, C. G., Carey, B. E., Krueger, B. F., \& Ross, S. R. (2016). Ten aspects of the Big Five in the Personality Inventory for DSM-5. Personality Disorders: Theory, Research, and Treatment, 7, 113123.

DeYoung, C. G., \& Krueger, R. F. (2018a). A cybernetic theory of psychopathology. Psychological Inquiry, 29, 117-138.

DeYoung, C. G., \& Krueger, R. F. (2018b). Understanding psychopathology: Cybernetics and psychology on the boundary between order and chaos. Psychological Inquiry, 29, 165-174.

DeYoung, C. G. \& Rueter, A. R. (2016). Impulsivity as a personality trait. In K. D. Vohs \& R. F. Baumeister (Eds.). Handbook of Self-Regulation: Research, Theory, and Applications (Third edition, pp. 345-363). New York: Guilford Press.

DeYoung, C. G., \& Weisberg, Y. J. (2019). Cybernetic approaches to personality and social behavior. In M. Snyder \& K. Deaux (Eds). Oxford handbook of personality and social psychology, Second edition (387-414). New York: Oxford University Press.

Gray, J. A. (2004). Consciousness: Creeping up on the hard problem. New York: Oxford University Press.

Gray, J. A., \& McNaughton, N. (2000). The neuropsychology of anxiety: An enquiry into the function of the septo-hippocampal system. New York, NY: Oxford University Press.

Haslam, N., McGrath, M. J., Viechtbauer, W., \& Kuppens, P. (2020). Dimensions over categories: a meta-analysis of taxometric research. Psychological Medicine. DOI: https://doi.org/10.1017/S003329172000183X.

Heyman, G. M. (2013). Quitting drugs: Quantitative and qualitative features. Annual Review of Clinical Psychology, 9, 29-59.

Kendell, R. E. (1975). The concept of disease and its implications for psychiatry. The British Journal of Psychiatry, 127, 305-315. 
Kotov, R., Krueger, R. F., Watson, D., Achenbach, T. M., Althoff, R. R., Bagby, R. M., ... \& Eaton, N. R. (2017). The Hierarchical Taxonomy of Psychopathology (HiTOP): A dimensional alternative to traditional nosologies. Journal of Abnormal Psychology, 126(4), 454-478.

Leshner, A. I. (1997). Addiction is a brain disease, and it matters. Science, 278(5335), 45-47.

Lewis, M. (2017). Addiction and the brain: Development, not disease. Neuroethics, 10, 7-18.

Markon, K. E., \& Krueger, R. F. (2005). Categorical and continuous models of liability to externalizing disorders: A direct comparison in NESARC. Archives of General Psychiatry, 62, 1352-1359.

Miller, G. A., Galanter, E., \& Pribram, K. H. (1960). Plans and the structure of behavior. New York: Holt.

National Institute on Drug Abuse; National Institutes of Health; U.S. Department of Health and Human Services (2018). The National Institute on Drug Abuse media guide.

Powers, A. R., Kelley, M. S., \& Corlett, P. R. (2017). Varieties of voice-hearing: Psychics and the psychosis continuum. Schizophrenia Bulletin, 43 84-98.

Powers, W. T. (1973). Behaviour: The control of perception. Chicago, IL: Aldine.

Seth, A. K. (2015). The cybernetic bayesian brain: From interoceptive inference to sensorimotor contingencies. In T. Metzinger \& J. M. Windt (Eds). Open MIND: 35(T). Frankfurt am Main: MIND Group.

Wakefield, J. C. (1992). Disorder as harmful dysfunction: A conceptual critique of DSM-III-R's definition of mental disorder. Psychological Review, 99, 232-247.

Wakefield, J. C. (2007). The concept of mental disorder: Diagnostic implications of the harmful dysfunction analysis. World Psychiatry, 6(3), 149-156.

Waller, R., Gardner, F., \& Hyde, L. W. (2013). What are the associations between parenting, callousunemotional traits, and antisocial behavior in youth? A systematic review of evidence. Clinical Psychology Review, 33(4), 593-608.

Walton, K. E., Ormel, J., \& Krueger, R. F. (2011). The dimensional nature of externalizing behaviors in adolescence: Evidence from a direct comparison of categorical, dimensional, and hybrid models. Journal of Abnormal Child Psychology, 39, 553-561.

Widiger, T. A., \& Samuel, D. B. (2005). Diagnostic categories or dimensions? A question for the Diagnostic and Statistical Manual of Mental Disorders-Fifth Edition. Journal of Abnormal Psychology, 114(4), 494-504.

Widiger, T. A., \& Sankis, L. M. (2000). Adult psychopathology: Issues and controversies. Annual Review of Psychology, 51(1), 377-404.

Widiger, T. A., Trull, T. J. (1991). Diagnosis and clinical assessment. Annual Review of Psychology, 42, 109-133.

Wiener, N. (1948). Cybernetics - or control and communication in the animal and the machine. New York, NY: MIT Press/Wiley.

Wouters, A. G. (2003). Four notions of biological function. Studies in History and Philosophy of Science Part C: Studies in History and Philosophy of Biological and Biomedical Sciences, 34, 633-668.

Wright, A. G. C., Krueger, R. F., Hobbs, M. J., Markon, K. E., Eaton, N. R., \& Slade, T. (2013). The structure of psychopathology: Toward an expanded quantitative empirical model. Journal of Abnormal Psychology, 122, 281-294. 